\title{
PROCESSAMENTO DO PRESUNTO “COOK-IN” DE CORDEIROS
}

\author{
PROCESSING OF COOK-IN HAM OF LAMBS
}

\author{
Eliane Mattos Monteiro ${ }^{1}$ Nelcindo Nascimento Terra ${ }^{2}$
}

\section{RESUMO}

Este trabalho teve por objetivo desenvolver tecnologia para produto curado (presunto “cook-in"), com pernis de cordeiros cruza Texel x Corriedale em associação com tratamentos tecnológicos (massagem em "tumbler" e processo "cookin”). $O$ estudo foi desenvolvido pela EMBRAPA/CPPSUL e Universidade Federal de Santa Maria, RS, Brasil. Após as análises da composição química, a carne foi injetada manualmente com $20 \%$ de salmoura composta por água + gelo $79 \%$, cloreto de sódio $7,52 \%$, condimento para presunto $4,70 \%$, fosfatos $1,97 \%$, sais de cura 1,88\%, sacarose $3,38 \%$ e glutamato monossódico $0,19 \%$. Os presuntos foram avaliados quanto à composição química (umidade, proteína, gordura, cinzas, pigmentos totais e pH), parâmetros sensoriais (cor, aroma, sabor, textura e aceitabilidade) e rendimento. Uma das principais características dos presuntos obtidos com pernil de cordeiros cruza Texel $x$ Corriedale foi o baixo conteúdo de gordura associado ao bom rendimento e à excelente aceitabilidade.

Palavras-chave: presunto, pernis de cordeiro, "tumbler" e sais de cura.

\section{SUMMARY}

The aim of this study was to develop technology for the curing lambs (cook-in hams) which were manufactured from the legs of crossbred Texel $x$ Corriedale lambs in association with technologic treatment (massaging in tumbler and cook-in process). The experiment was conducted at the EMBRAPACPPSUL/UFSM, RS, Brazil. After the evaluation of the chemical composition, the meat was injected with it manually - $20 \%$ of brine containing water $79 \%$, salt $7.52 \%$, curing salts $1.88 \%$, sucrose $3.38 \%$, ham condiments $4.70 \%$, phosphate $1.97 \%$ and sodium glutamate $0.19 \%$. The ham quality was evaluated by analysis of its chemical composition (moisture, protein, ash, fat, $p H$ ), sensory properties (color, aroma, texture, acceptability) and yield. The main characteristics of lamb hams were low fat contents associated with excellent acceptability and good yield.

Key words : ham, lamb leg, tumbler and curing salts.

\section{INTRODUÇÃO}

A utilização da carne ovina em produtos cárneos curados defumados (HAND et al., 1992), emulsionados (BALIGA \& MADAIAH, 1970; KLETTNER et al., 1989; PINHEIRO, 1989) e salgados (ZAPATA et al., 1990 ) já foi constatada.

$\mathrm{Na}$ elaboração do presunto, alguns parâmetros na matéria prima $(\mathrm{pH}$, pigmentos totais, proteína, gordura, umidade e cinzas) e na salmoura (temperatura, $\mathrm{pH}$ e concentração dos ingredientes), em associação a procedimentos tecnológicos adequados, como a massagem no "tumbler" e método "cook-in", podem assegurar a qualidade final do presunto ( SMITH, 1986; REICHERT, 1988).

A massagem mecânica no"tumbler", em associação com alguns ingredientes de cura (sais e fosfatos), contribui para uma rápida difusão da salmoura, promove a formação do exsudato protéico, o qual aumenta a coesão nas peças de carne com reflexos positivos para retenção da salmoura, maciez e cor do presunto. Estudos demonstram que as propriedades funcionais das proteínas, como solubilidade, viscosidade, aumento de retenção de água, retenção de gordura e geleificação são aumentadas quando se utiliza a massagem no "tumbler"(KRAUSE $\boldsymbol{e} t$ al., 1978; CASSIDY et al., 1978). Enquanto o processo "cook-in" apresenta como principais vantagens maior coesão nas peças de carne, aumento no rendimento do presunto e, por ser cozido na própria embalagem de fabricação (filme plástico, termoformável -resistente ao calor ) resulta um produto com uma vida útil mais prolongada. Os objetivos deste trabalho foram: 1) avaliar a composição química da

\footnotetext{
${ }^{1}$ Médico Veterinário, Doutor, Pesquisador, EMBRAPA/CPPSUL, CP 242, 964000-970, Bagé, RS, E mail : eliane@cppsul.embrapa.br.. Autor para correspondência.

${ }^{2}$ Farmacêutico, PhD., Professor Titular do Departamento de Ciência e Tecnologia dos Alimentos, Universidade Federal de Santa Maria, Santa Maria, RS
} 
matéria prima (umidade, proteínas, cinzas, $\mathrm{pH}$ e pigmentos totais); 2) elaborar presunto "cook-in", com pernis de cordeiros cruzas submetidos à massagem mecânica ("tumbler"); 3) avaliar através da análise sensorial (cor, aroma, sabor e textura) a aceitabilidade do presunto; 4) avaliar no presunto "cook-in" a composição química (umidade, proteínas, cinzas, $\mathrm{pH}$ e pigmentos totais).

\section{MATERIAL E MÉTODOS}

Os cordeiros utilizados neste estudo foram provenientes de cruzamento entre carneiros da raça Texel e ovelhas Corriedale, manejados em pastagem cultivada de inverno no CPPSUL/ EMBRAPA- Bagé/RS, abatidos com idade de 120 dias no Frigorífico Alegretense - Alegrete, RS. Decorridas vinte e quatro horas após o abate, foram retirados os pernis das carcaças, que foram embalados e congelados, para posterior processamento. Este foi realizado no Departamento de Ciência e Tecnologia dos Alimentos da Universidade Federal de Santa Maria, RS.

$\mathrm{Na}$ elaboração do presunto "cook-in", a avaliação do $\mathrm{pH}$ e da temperatura da matéria prima foram determinantes para o processamento. Estabeleceram-se como ideais o $\mathrm{pH}$ na faixa de 5,8 e a temperatura entre $2-4^{\circ} \mathrm{C}$; pernis que estivessem fora deste padrão foram rejeitados. Posteriormente, realizou-se a toalete nos pernis. Os ingredientes da salmoura foram adicionados obedecendo a seguinte ordem: fosfatos, sal, ingredientes de cura, condimentos e, por último, o ascorbato. $\mathrm{O} \mathrm{pH}$ final da salmoura foi estabelecido em torno de 9,0 (ajustado com carbonato de cálcio) e a temperatura em $3^{\circ} \mathrm{C}$. A salmoura básica foi composta de água +gelo $77,53 \%$, cloreto de sódio $9,22 \%$, condimentos para presunto $6,54 \%$, sacarose $3,32 \%$, glutamato monossódico $0,18 \%$, sais de cura $1,84 \%$, fosfatos 0,23 e ascorbato 1,10\% (PINHEIRO, 1989). Para cada forma de presunto de $1 \mathrm{~kg}$, utilizaram-se em torno de $0,800 \mathrm{~kg}$ de carne limpa (massa muscular), que foram injetadas manualmente com $20 \%$ da salmoura. Posteriormente, as peças de carne foram colocadas em bandejas plásticas e resfriadas a ${ }^{\circ} \mathrm{C}$, por 12 horas. Decorrido este período, realizou-se o massageamento por um período de 16 horas, com intervalos de 10 minutos entre cada hora em "tumbler" da marca SULMAQ, com capacidade para $50 \mathrm{~kg}$, com 22rpm (rotações por minuto) e camisa dupla para refrigeração. Após, as peças de carne permaneceram 12 horas em refrigeração para terminar o processo de cura. Em seguida, efetuaram-se a embalagem a vácuo, a pesagem e a termo-retração do saco plástico, em água a $80^{\circ} \mathrm{C}$. Para as enformagens utilizaram- se formas de aço inox com capacidade para $1 \mathrm{~kg}$ e o cozimento foi realizado durante uma hora a $60^{\circ} \mathrm{C}$, uma hora a $65^{\circ} \mathrm{C}$ e meia hora a $73^{\circ} \mathrm{C}$. Após o cozimento, ocorreu um resfriamento rápido em água fria $\left( \pm 1^{\circ} \mathrm{C}\right)$. Posteriormente, os presuntos enformados foram colocados em refrigeração a $5^{\circ} \mathrm{C}$, por doze horas, pesados e desenformados (figura 1).

As amostras da matéria prima e do presunto foram avaliadas quanto à composição centesimal (umidade, proteína, gordura e cinzas), conforme AOAC (1990). Os pigmentos totais e o $\mathrm{pH}$ foram determinados de acordo com TERRA \& BRUM (1988). O rendimento foi determinado através da diferença entre a pesagem da carne, antes da massagem mecânica no "tumbler", e a do presunto, após resfriamento, dividido pelo peso antes do tambleamento e multiplicado por 100, adaptado de GILLET et al (1981)

A análise sensorial foi realizada com amostras de presunto escolhidas ao acaso, fatiadas com espessura de $3 \mathrm{~mm}$, por um painel sensorial de

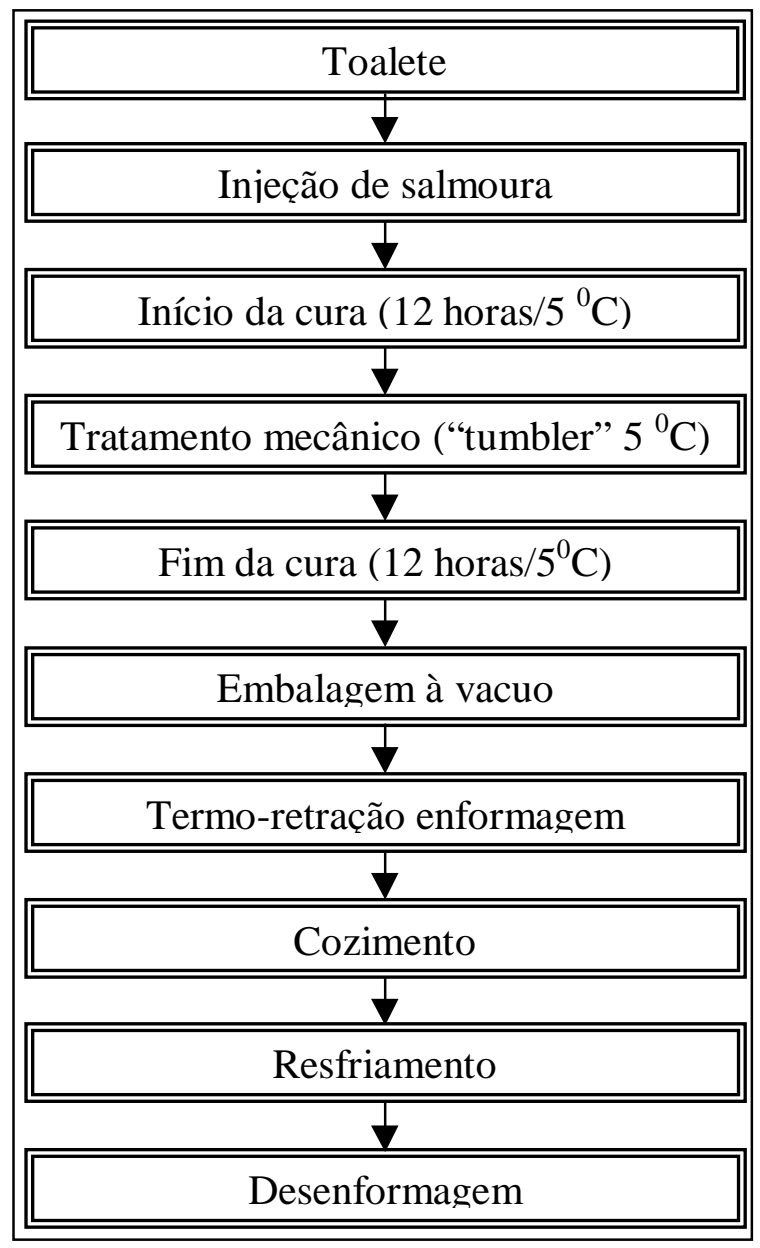

Figura 1 - Fluxograma do presunto "cook-in”. 
seis pessoas previamente treinadas no Departamento Ciência e Tecnologia dos Alimentos da Universidade Federal de Santa Maria. Utilizou-se uma escala hedônica para avaliar cor, aroma, sabor, textura, com os conceitos: 0 - 5,0 inaceitável; 5,1 - 7,0 regular; 7,1 - 8,0 bom/boa; 8,1 - 9,0 muito bom/muito boa. Considerou-se a média dos conceitos entre os quatros parâmetros como aceitabilidade, sendo que o valor 9,0 representou ótima aceitabilidade, ou seja, muito bom/ boa a cor, o aroma, o sabor, e a textura e, 0 - valor inaceitável. Em paralelo, utilizou-se um painel composto por 35 consumidores potenciais de presunto que, através de fichas, atribuíram notas aos diferentes parâmetros (MONTEIRO, 1984). As médias e os desvios padrões foram realizados de acordo com CHAVES (1980).

\section{RESULTADOS E DISCUSSÃO}

Os resultados das médias e os desvios para as variáveis $\mathrm{pH}$, pigmentos totais e composição centesimal (umidade, proteína, gordura e cinzas) encontram-se na tabela 1.

$\mathrm{O}$ pH final da carne é dependente da glicólise post-mortem e pode estar asssociado às condições pré-abate, à excitabilidade do animal, ao método de abate, ao potencial glicolítico do músculo e à capacidade tampão, à temperatura de resfriamento das carcaças, entre outros (LAWRIE, 1985). Neste sentido, alguns cuidados foram tomados, como o transporte, o carregamento e descarregamento adequados dos cordeiros da EMBRAPA ao frigorífico. Os animais tiveram um período de jejum e descanso, com dieta hídrica, para recompor as reservas musculares de glicogênio exauridas pelo estresse do embarque, transporte e desembarque. A temperatura de resfriamento das carcaças foi controlada. Todos estes cuidados resultaram num $\mathrm{pH}$ final normal (tabela 1) e dentro da faixa descrita por SHORTOSE (1978), KOOHMARAIE et al. (1991) e HAND $\boldsymbol{e t}$ al. (1992).

Ainda considerando o $\mathrm{pH}$ final da carne, JUDGE $\boldsymbol{e t}$ al. (1989) destacam a sua participação na cor, na capacidade de retenção de água e, consequientemente, nas perdas durante a cocção do pre-

Tabela 1 - Médias e desvios da composição química da matéria prima.

\begin{tabular}{lcccccc}
\hline & $\begin{array}{c}\text { Umidade } \\
\mathrm{g} \%\end{array}$ & $\begin{array}{c}\text { Proteína } \\
\mathrm{g} \%\end{array}$ & $\begin{array}{c}\text { Gordura } \\
\mathrm{g} \%\end{array}$ & $\begin{array}{c}\text { Cinzas } \\
\mathrm{g} \%\end{array}$ & $\begin{array}{c}\text { Pigmentos } \\
\mathrm{ppm}\end{array}$ & $\mathrm{pH}$ \\
\hline $\begin{array}{l}\text { Matéria }- \\
\text { prima }\end{array}$ & $\begin{array}{c}76,43 \\
( \pm 1,31)\end{array}$ & $\begin{array}{c}20,45 \\
( \pm 1,24)\end{array}$ & $\begin{array}{c}2,10 \\
( \pm 0,10)\end{array}$ & $\begin{array}{c}1,20 \\
( \pm 0,11)\end{array}$ & $\begin{array}{c}130,00 \\
( \pm 1,87)\end{array}$ & $\begin{array}{c}5,80 \\
( \pm 0,12)\end{array}$ \\
\hline
\end{tabular}

sunto. Conforme os autores, o $\mathrm{pH}$ da carne deve ser iqual ou superior a 5,8, para assegurar-se uma boa capacidade de retenção de água (CRA) do presunto.

As diferentes frações que compõem o músculo são de fundamental importância na qualidade do produto final. A cor característica dos produtos curados é obtida a partir da combinação do óxido nítrico com a mioglobina. Por outro lado, o valor percentual da mioglobina está associado ao tipo de metabolismo da fibra muscular, que pode sofrer variações decorrentes da espécie (SOLOMON \& CARPENTER, 1988), do exercício (AALHUS \& PRICE, 1991), do tipo de músculo (PEARSON \& YOUNG, 1989), de fatores genéticos (SOLOMON \& CARPENTER, 1985) e da alimentação (SEIDMAN \& CROUSE, 1986; MALTIN $\boldsymbol{e t}$ al.,1998). Além dos fatores acima listados, a idade do animal também é um fator importante a ser considerado, pois o teor de mioglobina presente no músculo aumenta proporcionalmente com ela. Conforme dados apresentados na tabela 1 , o valor médio dos pigmentos totais nos pernIs de cordeiros foi de $130,00( \pm 1,87)$ ppm, bem inferior aos 305,44ppm descritos por PINHEIRO (1989), em pernil de ovelha de descarte.

$\mathrm{Na}$ tabela 1 , encontram-se os dados referentes À composição centesimal. O pernil de cordeiro caracterizou-se por apresentar baixo teor de gordura 2,10 $( \pm 0,10) \mathrm{g} \%$-(tabela 1), cujo valor foi bem inferior aos $8,25 \mathrm{~g} \%$ descritos por PINHEIRO (1989), para ovelha de descarte.

A salmoura básica, que originou a formulação do presunto "cook-in", foi desenvolvida para presunto de ovelha de descarte, já descrita na metodologia. A partir desta formulação (metodologia), procurou-se ajustar a concentração dos ingredientes da salmoura (tabela 2), visando à obtenção de um presunto com características sensorais desejáveis e com ótimo rendimento. Quanto ao tempo de massagem mecânica no "tumbler", estabeleceu-se em dezesseis horas com intervalos de dez minutos entre cada hora, para perfeita extração das proteínas e coesão das peças de carne. De acordo com CASSIDY et al. (1978), o período de repouso na massagem mecânica no "tumbler" permite uma maior difusão dos sais de cura, potencializando a ação do sal e dos fosfatos. Conforme os dados apresentados na tabela 4 , o rendimento do presunto foi de $98,66 \%$. Este resultado foi superior aos $85,12 \%$ encontrados por PINHEIRO (1989), que elaborou presunto ovino, tendo como matéria prima pernil de ovelha de descarte, sem a utilização do "tumbler" e aos 
Tabela 2 - Composição da salmoura desenvolvida (\%).

\begin{tabular}{lr}
\hline & 79,00 \\
Água + gelo & 7,52 \\
Sal & 4,70 \\
Condimentos para presunto & 1,97 \\
fosfatos & 1,88 \\
Sais de cura & 1,13 \\
Ascorbato & 3,38 \\
Sacarose & 0,19 \\
Glutamato monosódico & \\
\hline
\end{tabular}

92,54\% obtidos por KRAUSE $\boldsymbol{e t}$ al. (1978) em presunto suíno submetido à ação do "tumbler".

A cor dos produtos curados depende da concentração dos pigmentos presentes no músculo. O teor de pigmentos totais $130,00( \pm 1,87)$ ppm na matéria prima foi o fator determinante para coloração clara 133,41 $( \pm 0,02)$ ppm e para boa pontuação $8,4( \pm 0,10)$ do presunto de cordeiro (tabela 3). PINHEIRO (1989) encontrou valores bem superiores para os pigmentos hemitotais $(315,10 \mathrm{ppm})$ para presunto de ovelha descarte e este parâmetro contribuiu para baixa aceitabilidade do presunto.

Locker \& Cured Lamb apud LAWRIE (1980) observou que dois parâmetros sensorais (cor vermelho-escura e pouca suculência) foram determinantes para a rejeição de presunto elaborado com pernil de ovelha de descarte, quando comparado com o elaborado com pernil de cordeiro que se caracterizou por ser um produto de excelente qualidade, comparável ao de suíno.

Dentre os parâmetros sensoriais avaliados, a textura do presunto de cordeiro apresentou a melhor pontuação (tabela 3) e estes valores podem ser atribuídos a um conjunto de fatores como o $\mathrm{pH}$, a formulação, o tratamento mecânico e a matéria prima utilizada (carne de cordeiro). Por outro lado, todos os outros parâmetros avaliados pelos painelistas tiveram muito boa pontuação (tabela 3 ).

Tabela 3 - Média e desvio da análise sensorial do presunto "cook-in”.

\begin{tabular}{cccccc}
\hline & Cor & Aroma & Sabor & Textura & Aceitabilidade \\
\hline Pontuação & $\begin{array}{c}8,4 \\
( \pm 0,10)\end{array}$ & $\begin{array}{c}8,3 \\
( \pm 0,30)\end{array}$ & $\begin{array}{c}8,4 \\
( \pm 0,10)\end{array}$ & $\begin{array}{c}8,7 \\
( \pm 0,10)\end{array}$ & $\begin{array}{c}8,5 \\
( \pm 0,10)\end{array}$ \\
\hline
\end{tabular}

Conceitos: 0 - 5,0 inaceitável; 5,1 - 7,0 regular; 7,1 - 8,0 bom/boa; 8,1 - 9,0 muito bom/boa.
HAND et al. (1992) observaram no painel sensorial de presunto defumado, elaborado com pernil de capão, de cordeiro e de suíno que a textura e a suculência apresentaram resultados similares $(\mathrm{P}>0,005)$.

$\mathrm{Na}$ composição centesimal (tabela 4), comparando-se com os dados de HAND $\boldsymbol{e t}$ al. (1992), observou-se que o presunto "cook-in" apresentou teor de proteína 20,45 $( \pm 1,24) \mathrm{g} \%$, semelhante ao presunto defumado de capão 20,5 $( \pm 1,24) \mathrm{g} \%$ e superior ao presunto defumado de cordeiro que foi de 19,3 ( $\pm 1,2) \mathrm{g} \%$. Enquanto, para o teor de gordura os resultados do presunto "cookin" foram inferiores aos de presunto defumado de cordeiro 3,5 $( \pm 0,9) \mathrm{g} \%$ e de capão 4,6 $( \pm 0,4) \mathrm{g} \%$.
Tabela 4 - Médias e desvios da composição química e rendimento do presunto "cook-in".

\begin{tabular}{ccccccc}
\hline $\begin{array}{c}\text { Umidade } \\
\mathrm{g} \%\end{array}$ & $\begin{array}{c}\text { Proteína } \\
\mathrm{g} \%\end{array}$ & $\begin{array}{c}\text { Gordura } \\
\mathrm{g} \%\end{array}$ & $\begin{array}{c}\text { Cinzas } \\
\mathrm{g} \%\end{array}$ & $\begin{array}{c}\text { Pigmentos } \\
\mathrm{ppm}\end{array}$ & $\mathrm{pH}$ & $\begin{array}{c}\text { Rend } \\
\mathrm{g} \%\end{array}$ \\
\hline $\begin{array}{c}78,00 \\
( \pm 0,03)\end{array}$ & $\begin{array}{c}20,60 \\
( \pm 0,01)\end{array}$ & $\begin{array}{c}1,74 \\
( \pm 0,02)\end{array}$ & $\begin{array}{c}( \pm 0,08 \\
( \pm 0,04)\end{array}$ & $\begin{array}{c}133,41 \\
( \pm 0,02)\end{array}$ & $\begin{array}{c}( \pm 0,10 \\
( \pm 01)\end{array}$ & $\begin{array}{c}( \pm 0,06) \\
\end{array}$
\end{tabular}

\section{CONCLUSÕES}

O presunto de cordeiro "cook-in" caracteriza-se por ser um produto com baixo teor de gordura, alto valor protéico, ótima aceitabilidade no painel sensorial e bom rendimento. Com base nos resultados obtidos neste trabalho e consideradas as condições utilizadas no estudo, conclui-se que é viável a utilização do pernil ou quarto de cordeiro cruza Texel x Corriedale, utilizando tratamentos tecnológicos ("tumbler" e processo "cook-in"). Porém, cabe salientar que, embora o presunto "cookin" tenha tido ótima aceitabilidade, novos estudos deverão ser conduzidos visando a melhor avaliar alguns parâmetros de qualidade do produto.

\section{AGRADECIMENTOS}

Os autores agradecem a colaboração dos produtores de Santana do Livramento/RS e, em especial, David Fontoura Martins e Claudino Loro, pelo apoio para o desenvolvimento deste trabalho. 


\section{REFERÊNCIAS BIBLIOGRÁFICAS}

AALHUS, J.L., PRICE, M.A. Endurance-exercised growing sheep: post-mortem and histological changes in skeletal muscles. Meat Science, v. 43, p. 43-56, 1991.

ASSOCIATION OF OFFICIAL ANALYTICAL CHEMISTS. Official methods of analysis of the Association of Official Analytical Chemists. 15. ed. Arlington: AOAC, 1990. p. 931.

BALIGA, B.R. MADAIAH, N. Quality of sausage emulsion prepared from mutton. Journal Food Science, v. 35, p. 383385,1970 .

CHAVES, J.B.P. Avaliação sensorial dos alimentos. Viçosa MG: Imprensa Universitária, 1980. 35 p.

CASSIDY, R.D., OCKERMAN, H.W., KROL, B. Effect of tumbling method, phosphate level and final cook temperature on histological characteristics of tumbled porcine muscle tissue. Journal of Food Science, v. 43, p. 1514-1518, 1978.

GILLET, T.A., CASSIDY, R.D., SIMON, S. Effect on bind, yield and colors hams. The continous massaging. Journal of Food Science, v. 46, p. 1681-1684, 1981.

HAND, L.W., DUNLAVY, K.A., LAMKEY, J.W., et al. Low fat cured and mutton. Products Animal Science Research Report, MP 136, p. 27-32, 1992.

JUDGE, M.D., ABERLE, E.D., FORREST, J.C., et al. Principles of meat science. Dubuque: Kendall/Hunt, 1989. p. 11-56.

KRAUSE, R.J., OCKERMAN, H.L., KROL, B. Influence of tumbling time, trim and sodium tripolyphosphate on quality and yield of cured hams. Journal of Food Science, v. 43, p. 853-855, 1978.

KOOHMARAIE, M., WHIPLE, G., KRETCHAMAR, D.H., et al. Postmortem proteolysis in Longissimus muscle from beef, lamb and pork carcasses. Journal Animal Science, v. 69, p. 617-624, 1991

LAWRIE, R.A. Meat science. 4. ed. Oxford, England: Pergamon, 1980. Cap.7. p. 181-193.

LAWRIE, R.A. Meat Science. 5. ed. Oxford, England: Pergamon, 1985. Cap. 5. p. 74-91.

MONTEIRO, C.L.B. Técnicas de avaliação sensorial. Curitiba, PR: Imprensa Univesitária, 1984.90 p.
MALTIN, C.A.S., SINCLAIR, K.D.S., WARRISS, P.D.S, et al. The effects of age at slaughter, genotype and finishing system on the biochemical properties, muscle fiber characteristics and eating quality of bull beef suckled calves. Animal Production, v.66, p. 341-348, 1998.

PEARSON, A.M., YOUNG, R.B. Muscle and meat biochemistry. San Diego: Academic, 1989. Cap. 9. p. 235265 .

PINHEIRO, E.M. Processamento da carne de ovino adulto. Santa Maria- RS, 1989. 81p. Dissertação (Mestrado em Ciência e Tecnologia dos Alimentos) - Curso de Pósgraduação em Ciência e Tecnologia dos Alimentos, Universidade Federal de Santa Maria, 1989.

REICHERT, J.E. Tratamiento térmico de los produtos cárnicos. Zaragosa, Espanha: Acribia, 1988. 175 p.

SHORTOSE, W.R. Effects os level of feeding, pre-slaughter stress and method of slaughter on postmortem glycolysis of sheep muscles. Meat Science, v. 2, p. 189-198, 1978.

SOLOMON, M.B., CARPENTER, J.W. Fiber types in the longissimus muscle from water Buffalo and selected domestic beef breed. Journal Animal Science, v. 13, p. 129-135, 1985.

SOLOMON, M.B., CARPENTER, J.W. Simultaneous histochemical determination of three fiber types single sections of ovine, bovine and porcine sleletal muscle. Journal Animal Science, v. 66, p. 255-264, 1988.

SEIDMAN, S.C.S., CROUSE, J.D. The effects of sex condition, genotype and diet on bovine muscle fiber characteristics. Meat Science, v. 17, n. 3, p. 55-72, 1986.

SMITH, G.R. Processing and fabrication. In: BECHTEl, P.J. Muscle as Food. London: Academic, 1986. Cap. 5. p. 201218.

SMITH, D.M. Meat proteins: functional properties in comminuted meat products. Food Technology, v. 41, p. 166$121,1988$.

TERRA, N.N., BRUM, M.A.R. Carne e seus derivados Técnicas de controle de qualidade. São Paulo: Nobel, 1988. $121 \mathrm{p}$.

ZAPATA, J.F.F., LEWARD, D.A., LAWRIE, R.A. Preparation and storage stability of dried salted mutton. Mead Science, v. 27 , p. $109-118,1990$. 